\title{
Patents made simple
}

\author{
Michael Francisco
}

Patent Strategy for Researchers and Research Managers, Second Edition By H. Jackson Knight

John Wiley \& Sons; \$105, 201 pp, hardcover, ISBN 0471492604, 2001

Asking a researcher to learn about the intricacies of the patent system sometimes seems tantamount to asking him or her to climb Mount Everest blindfolded. Such is the complexity of the subject that most are happy to leave their discoveries in the hands of a patent lawyer or technology transfer office. Yet close collaboration between the inventor and the patent agent in the preparation and filing of a patent application may make the difference between a patent's being issued, rejected, orworse-later rendered invalid.

Patent Strategy for Researchers and Research Managers attempts not only to educate the researcher about the basic principles of the patent system, but also to provide a guide through the entire process-from deciding whether an invention is patentable, to working with a

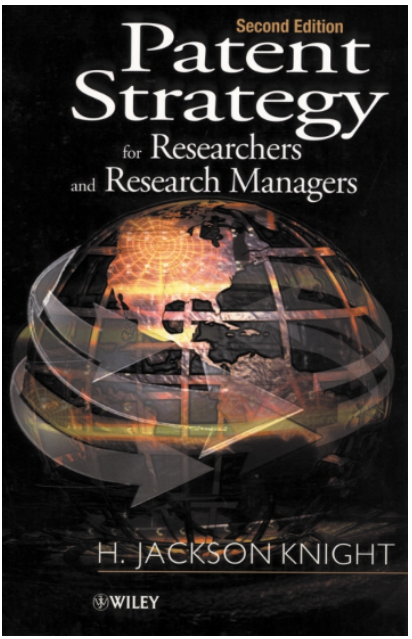

Focusing on the intricacies of patent law would have been a colossal task. Instead, Knight delves directly into the process of developing a patent strategy, in both the narrow (preparing the best possible patent applications) and broad (generating the best possible patent portfolio for a business) senses. This impressive, well-organized section constructs a three-tiered definition of a patent strategy based on the traditional, military-based, dictionary meaning of the word. The military model is strikingly apt, with terms like 'enemy' and 'combat' readily convertible to the business-speak of 'competitors' and 'the marketplace.'

Subsequent chapters discuss issues that can arise when researchers work with patent agents and attorneys, and the final steps in disclosing and filing a patent application. The author's experience as both researcher and patent professional is invaluable here; he describes how each side looks at the same invention, and how they can best work together to ensure that the resulting patent application meets the goals set out as part of the organization's overall patent strategy. patent agent, to maintaining patents once they have been issued. Author $\mathrm{H}$. Jackson Knight, a senior patent specialist and former researcher with E.I. DuPont de Nemours \& Company, explains clearly the various choices patent-seekers must make in the course of filing an application and, more importantly, the concepts underlying them. His direct, concise style renders the most complex ideas understandable, without reverting to legalese, and contributes considerably to the value of this slim volume.

Most books about patent law tend to cater to patent professionals. But-fortunately for IP-challenged researchers-this one presupposes no prior knowledge of the patent system. A solid foundation is built in the first few chapters, as basic concepts of intellectual property and the value of patents are covered. Some common misconceptions regarding patents are also dispelled, such as the belief that a patent gives the holder the right to practice an invention. In fact, it only gives one the right to exclude others from practicing the invention without permission.
Though the characterization of researchers who are "more comfortable with absolutes" being confused by the gray areas in the everchanging patent system seems glib, the advice on patent practice and strategy outlined by the author should prove extremely useful, even to more seasoned inventors.

This second edition reflects the changes in patent law enacted since the book first appeared in 1996. In five short years, much has changed in the intellectual property landscape, prompted in large part by the startling pace of advances in the biotechnology and software industries. This book delivers on the promise of its title. Researchers in all fields, as well as their managers, will find it valuable for its insights into how patent professionals carry out their jobs. In the future, as recently issued patents continue to be tested in court, case law develops, and the patent system continues to evolve, books such as this will help to effectively manage the intellectual property that is crucial for organizations trying to stay competitive in the global marketplace. 